OPEN ACCESS

Edited by:

Nathalie Pamir

Oregon Health and Science University,

United States

Reviewed by:

Laurent Calvier,

University of Texas Southwestern Medical Center, United States

Robert Kiss,

McGill University, Canada

${ }^{*}$ Correspondence:

Daoquan Peng

pengdq@csu.edu.cn

Specialty section:

This article was submitted to Lipids in Cardiovascular Disease,

a section of the journal

Frontiers in Cardiovascular Medicine

Received: 27 August 2021

Accepted: 30 September 2021

Published: 29 October 2021

Citation:

Luo Y, Ren X, Weng S, Yan C, Mao Q and Peng D (2021) Improvements in High-Density Lipoprotein Quantity and

Quality Contribute to the

Cardiovascular Benefits by Anti-tumor Necrosis Factor Therapies in Rheumatoid Arthritis: A Systemic Review and Meta-Analysis. Front. Cardiovasc. Med. 8:765749.

doi: 10.3389/fcrm.2021.765749

\section{Improvements in High-Density} Lipoprotein Quantity and Quality Contribute to the Cardiovascular Benefits by Anti-tumor Necrosis Factor Therapies in Rheumatoid Arthritis: A Systemic Review and
Meta-Analysis

\author{
Yonghong Luo ${ }^{1}$, Xiaolei Ren ${ }^{2,3}$, Shuwei Weng ${ }^{1}$, Chunhui Yan ${ }^{4}$, Qiaoxia Mao ${ }^{5}$ and \\ Daoquan Peng ${ }^{1 *}$
}

${ }^{1}$ Department of Cardiovascular Medicine, The Second Xiangya Hospital, Central South University, Changsha, China, ${ }^{2}$ Department of Orthopedics, The Second Xiangya Hospital, Central South University, Changsha, China, ${ }^{3}$ Hunan Key Laboratory of Tumor Models and Individualized Medicine, The Second Xiangya Hospital, Central South University, Changsha, China, ${ }^{4}$ Department of Cardiovascular Medicine, Brain Hospital of Hunan Province, Changsha, China, ${ }^{5}$ Department of Cardiovascular Medicine, Loudi Central Hospital, Loudi, China

Objective: Inflammation plays important role in atherosclerotic cardiovascular diseases (CVDs), but the interaction between the inflammation and lipid profile is largely unrevealed in humans. Patients with rheumatoid arthritis (RA) suffer from a higher risk of CVDs. Decreased total cholesterol (TC) and high-density lipoprotein (HDL) were prevalent in patients with RA. Anti-tumor necrosis factor (TNF) therapies relieve disease activity and decrease CVDs risk in RA, but their comprehensive effects on the lipid profile are unclear. This study aims to investigate the changes in blood lipid profile along time in the patients with RA accepting anti-TNF therapies by meta-analysis.

Methods: The MEDLINE, the Embase, and the Cochrane Central Register of Controlled Trials (CENTRAL) were searched for eligible literature. Data of lipids were classified into short-, mid-, and long-term according to treatment duration. Meta-analyses were performed to compare the lipid levels before and after treatments.

Results: A total of 44 records and 3,935 patients were included in the meta-analyses. Anti-TNF therapies were associated with significant increase in TC [mean difference $(\mathrm{MD}):+0.14,+0.23$, and $+0.26 \mathrm{mmol} / \mathrm{l}$, respectively] and $\mathrm{HDL}$ (MD): +0.11 , +0.12 , and $+0.11 \mathrm{mmol} / \mathrm{l}$, respectively) in the short-, mid-, and long-term; anti-TNF therapies were associated with increased low-density lipoprotein (LDL) (MD: +0.06 mmol/l) and apolipoprotein A1 (ApoA1) (MD: +0.07 g/l) in the short-term, but not in the mid-term and long-term; triglyceride (TG) and apolipoprotein $B(A p o B)$ do not change significantly in all the periods; proatherosclerotic indexes (TC/HDL, ApoB/ApoA1, and LDL/HDL) tend to decrease in the short- and mid-term, but return to baseline in the long-term after TNF inhibition. 
Conclusion: Anti-TNF therapies were related to a long-term raised HDL level, which, together with evidence of improved HDL function, may contribute partially to the decreased CVDs risk by TNF inhibition.

Keywords: tumor necrosis factor, rheumatoid arthritis, high-density lipoprotein, lipid, meta-analysis

\section{INTRODUCTION}

Inflammation plays important role in atherosclerotic cardiovascular diseases (CVDs). Recently, two anti-inflammatory therapies, i.e., the interleukin-1 $\beta$ (IL-1 $\beta$ ) monoclonal antibody, canakinumab and colchicine, have brought encouraging results in reducing the residual risks in atherosclerosis in addition to and independent of lipid-lowering effect (1-3). However, the interaction between the inflammation and lipid profile is largely unrevealed in humans.

Patients with rheumatoid arthritis (RA) are at higher risk of CVDs, which can be partially explained by traditional risk factors of CVDs including smoking, hypertension, obesity, and diabetes. Interestingly, lipid profile in the patients with RA changes toward an "atheroprotective" direction. Patients with RA have lower blood total cholesterol (TC), low-density lipoprotein (LDL), and high-density lipoprotein (HDL) compared to the general population. The lower TC and LDL are unexpectedly associated with higher CVD risk, which is called the lipid paradox (4). Some of the anti-RA therapies are associated with altered lipid profile and decreased CVDs risk, indicating that chronic systemic inflammation contributes to the lipid paradox and additional risk of CVDs (5-7). Among the antiRA therapies, inhibition of tumor necrosis factor (TNF), an important proinflammatory cytokine that contributes to RA development, effectively ameliorates RA activity and reduces CVDs risk in the patients with RA (8). The mechanisms behind the CVD-protective role of anti-TNF therapies are poorly understood. Previous meta-analyses imply that an increase in HDL after anti-TNF therapies may contribute to CVD amelioration. However, the concomitant increase in TC, which is atherogenic, contradicts the potential benefits of HDL (911). Besides, LDL and triglyceride (TG) change vary among studies, making it confusing to interpret the effects of changes in the comprehensive lipid profile on CVDs. Lipid ratios, including atherogenic index (AI) (TC/HDL), apolipoprotein B/apolipoprotein A1 (ApoB/ApoA1), and LDL/HDL, may help to determine a combined effect of the changes in both the anti- and proatherogenic lipids, but previous meta-analyses seldom analyzed them systematically because of limited data. In addition, lipid changes after long-term anti-TNF treatments are seldom evaluated.

This study aims to systematically assess the changes in blood lipid profile after short-, mid-, and long-term anti-TNF therapies in patients with RA by meta-analysis of the literature. We also aim to review the evidence of altered lipoprotein functions after TNF inhibition in patients with RA, trying to investigate the possible effects of systemic inflammation inhibition on lipid profile, especially HDL.

\section{METHODS}

\section{Search Strategy}

Refer to Supplementary Material 1.

\section{Study Selection}

Study selection was performed by YL and XR independently. When divergency comes, a third person DP would make the final decision. Studies meet all the following criteria that were included for meta-analysis: (1) prospective studies; (2) with patients diagnosed with RA; (3) including any one of the antiTNF therapies: infliximab (IFX), etanercept (ETN), adalimumab (ADA), certolizumab, or golimumab; and (4) with mean, SD, sample size, and treatment duration of any one of the following lipid profile both before and after anti-TNF therapies are available (either directly available, can be estimated as described in the "data extraction" section, or available from the authors): TC, TG, HDL, LDL, TC/HDL (AI), ApoA1, ApoB, ApoB/ApoA1 ratio, or LDL/HDL ratio.

\section{Quality Assessment of Studies}

Quality assessment was performed by SW and CY independently. When divergency comes, a third person DP would make the final decision. Quality assessment was a combination based on: (1) the Cochrane Collaboration's tool for assessing the risk of bias in randomized trials (12), (2) the Newcastle-Ottawa Scale (NOS) for the cohort studies (13), (3) the methodological index for nonrandomized studies (MINORS) (14), (4) the quality assessment of diagnostic accuracy studies (QUADAS) tool for the diagnostic studies (15), and (5) potential factors that may affect lipid profile in the patients with RA. A total of 14 entries are evaluated for each included study as shown in Supplementary Table 3. Studies with at least nine scores are considered as high quality.

\section{Data Extraction}

Data extraction was performed by YL and XR independently. When inconsistency arose, a third person QM would double check the original reference. Mean \pm SD of lipid profile in the patients with RA before (baseline) and after (endpoint) antiTNF therapies was extracted. When mean \pm SD of lipid profile was not available in the articles or from the authors, mean was estimated from median if available (16) and SD was estimated from either SEM (17), interquartile range (IQR) (16), range (16), or CI (17). When either SD of baseline or endpoint was missing, estimate one from the other. When only baseline and change from baseline data were available, endpoint data were estimated by using baseline and change from baseline data (17). TC, HDL, and LDL levels in $\mathrm{mg} / \mathrm{ml}$ were converted to $\mathrm{mmol} / \mathrm{l}$ 
by multiplying by 0.02586 ; TG level in $\mathrm{mg} / \mathrm{ml}$ was converted to $\mathrm{mmol} / \mathrm{l}$ by multiplying by 0.01129 . The effects of anti-TNF therapies on lipid profile were divided into short-term (0-12 weeks), mid-term (13-26 weeks), and long-term (>26 weeks) effects. For reports that present lipid data from the same clinical trial, use the data from the latest report. For the short-term and mid-term effects, if lipid data at multiple time points were available, choose the latest time point for analysis. For the longterm effect, if lipid data at multiple time points were available, choose the latest time point if the latest time point was less than 1 year; otherwise, choose the earliest time point (in this way, we are able to let the long-term treatment duration reside in a similar period around 1 year as close as possible).

\section{Statistical Analysis}

Mean differences (MDs) with corresponding 95\% CIs were calculated by using a fixed-effects model when low heterogeneity was indicated; otherwise, meta-analyses were performed by using a random-effects model. Heterogeneity was assessed by using the $I^{2}$ statistic. Low heterogeneity was defined as $I^{2}<50 \%$ and $p$ $>0.05$ (17). In case of heterogeneity, subgroup analyses were performed according to quality score ( $\geq 9$ vs. $<9$ ); study design (randomized controlled study vs. prospective cohort study); RA duration ( $\geq 6$ vs. $<6$ months) (18); the Disease Activity Score-28 (DAS28) ( $>5.1$ vs. $\leq 5.1)(18)$; age ( $\geq 55$ vs. $<55$ years old); drug (IFX, ADA, ETN, and mixed); baseline lipid level (for TC: $\geq 5.2$ vs. $<5.2 \mathrm{mmol} / \mathrm{l}$, for TG: $\geq 1.7$ vs. $<1.7 \mathrm{mmol} / \mathrm{l}$, for $\mathrm{HDL}:>1.5$ vs. $\leq 1.5 \mathrm{mmol} / \mathrm{l}$, and for LDL: $\geq 3.4$ vs. $<3.4 \mathrm{mmol} / \mathrm{l}$ ) (19). For lipids with more than 10 studies available for analysis (17), metaregression was also performed to discover the potential sources of heterogeneity. Sensitivity analyses were performed to evaluate the robustness of the meta-analyses. The funnel plot, Begg's test, and Egger's test were performed to evaluate the potential publication bias when the number of studies included in the meta-analyses was no less than 10 (17). All the analyses were performed by Stata 12.0 software, Texas, USA.

\section{RESULTS}

\section{Search Results}

A total of 1,900 records were obtained from the primary search of the three databases. After removing duplicates, titles and abstracts of 1,694 records were screened, among which 1,534 records were excluded according to the inclusion criteria. Full text of 160 records was read, and finally, 44 records were included in the meta-analyses (Figure 1).

\section{Study Characteristics and Quality Assessment}

The study design, number of patients, female proportion, disease duration, the DAS28, age of the patient, drugs used, follow-up duration, lipid measurement, and lipid profile in each study were collected (Table 1). The baseline concomitant uses of drugs that may affect blood lipids were also listed including conventional disease-modifying antirheumatic drugs (cDMARDs), corticosteroids, and lipid-lowering drugs (e.g., statins) (Supplementary Table 1). A total of 3,935 patients were included in the study. Among the 44 studies included, 11 studies are randomized controlled trials (RCTs) and 33 studies are prospective cohort studies. Clinical trial registration numbers for RCTs are available in Supplementary Table 2. Six studies have more than one arm of the patients treated with anti-TNF therapies and each arm was considered an independent study. Most of the patients are female with RA duration for more than 6 months and with high disease activity (DAS28 > 5.1). Patients were treated with either IFX, ETN, or ADA and followed up for at least 2 weeks. Patients treated with golimumab or certolizumab (except in studies with mixed anti-TNF therapies) were not included in the current meta-analysis because of ineligibility or insufficient data for meta-analysis. For most of the included studies, fasting blood was used to measure lipids.

The quality of the included studies was assessed by the quality assessment lists consisted of 15 items that may affect the lipid outcomes (Supplementary Table 3). About nine studies are assessed as low quality (quality $<9$ ).

\section{Primary Outcomes}

\section{Short-Term Changes in Lipid Profile}

Short-term changes in lipid profile after anti-TNF treatments are summarized in Table 2 and the forest plots are shown in Figure 2. Short-term anti-TNF treatments are associated with a significant increase in blood TC (Figure 2A), LDL (Figure 2D), and ApoA1 (Figure 2F) without heterogeneity. Blood TG (Figure 2B) and ApoB (Figure 2G) show no significant changes without heterogeneity. HDL increased significantly with heterogeneity (Figure 2C). AI does not change with heterogeneity (Figure 2E). ApoB/ApoA1 ratio (Figure $2 \mathbf{H}$ ) and LDL/HDL ratio (Figure 2I) tend to decrease but do not reach statistical significance without heterogeneity.

To test the robustness of the meta-analyses, we performed the sensitivity analyses (Supplementary Figure 1). The ENTRACTE trial greatly influences the variation of pooled MD of TC, TG, HDL, and LDL because of a large patient number, but it does not change the direction of the results (Supplementary Figures 1A-D). After removing the ENTRACTE trial, the pooled MD of TC, HDL, and LDL increases more. The results of AI, ApoA1, ApoB, ApoB/ApoA1 ratio, and $L D L / H D L$ ratio are not affected by removing any one of the included studies (Supplementary Figures 1E-I).

The funnel plot, Begg's test, and Egger's test show that the pooled MD of TC and HDL is at high risk of publication bias, while another lipid profile is at low risk of publication bias (Supplementary Figures 2A-I). Because the ENTRACTE trial greatly influences the robustness of TC and HDL meta-analyses (Supplementary Figures 1A,C), we removed the ENTRACTE study and reperformed the analyses. Removing the ENTRACTE trial results in the symmetrical funnel plot and nonsignificant $p$-values of the Begg's test and Egger's test for TC and HDL (Supplementary Figure 3). Besides, removing the ENTRACTE study also significantly decreases the heterogeneity of the meta-analysis of short-term HDL changes (Supplementary Figure 3C), indicating the ENTRACTE trial as a potential source of heterogeneity. We re-examined the characteristics of the ENTRACTE trial. We found that the trial 


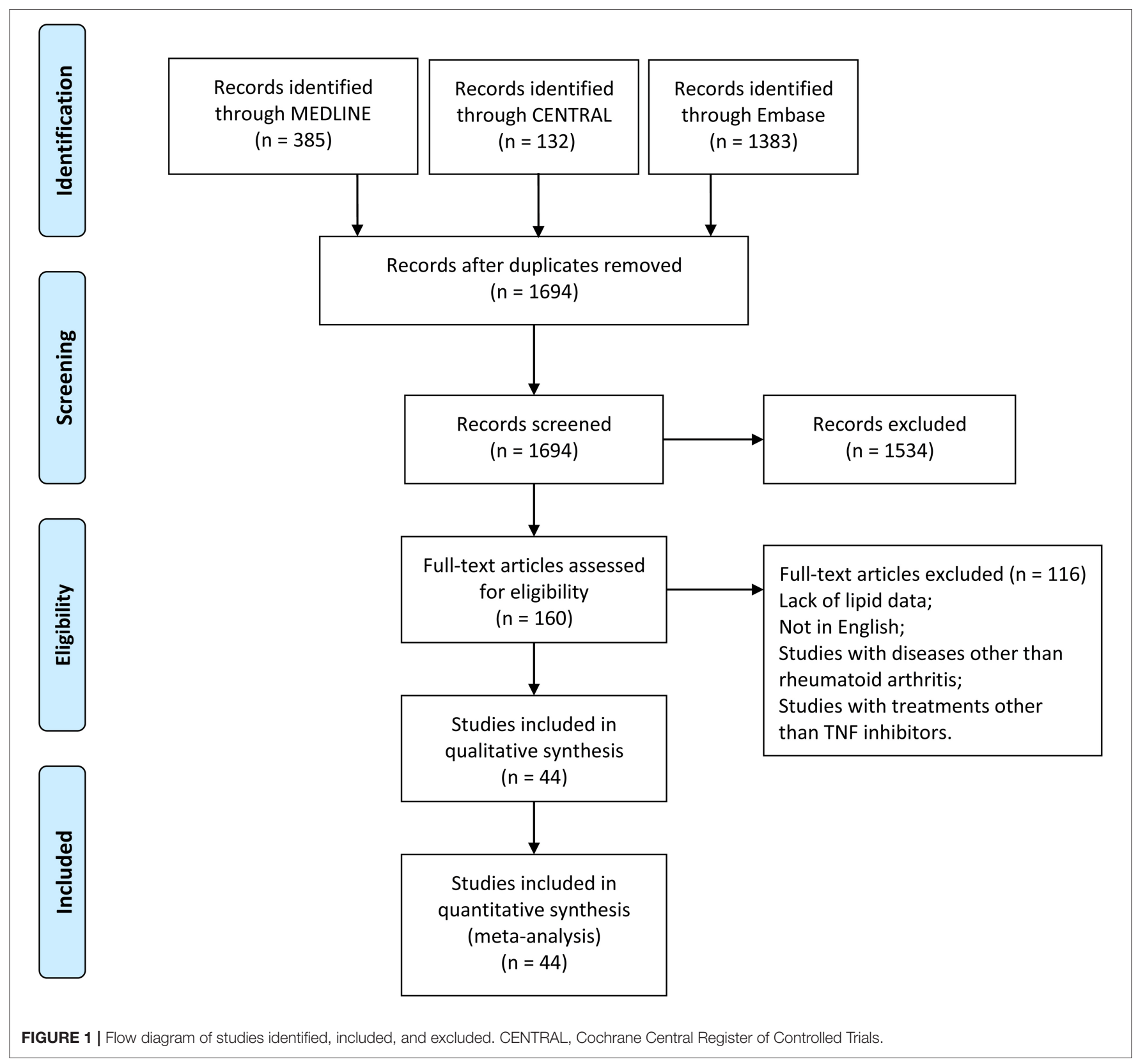

included patients with at least one traditional CVD risk factor or a history of CVD events, which may bring confounding factors that affect lipid profile (21). Also, concomitant use of cDMARDs, corticosteroids, and lipid-lowering therapies that may influence lipid profile was not well controlled in the trial, resulting in a low-quality score (Supplementary Table 3).

\section{Mid-term Changes in Lipid Profile}

Mid-term changes in lipid profile after anti-TNF treatments are summarized in Table 2 and the forest plots are shown in Figure 3. Mid-term anti-TNF treatments are associated with a significant increase in TC (Figure 3A) and HDL (Figure 3C) with heterogeneity. Similar to short-term, blood TG does not change without heterogeneity (Figure 3B). LDL (Figure 3D) and ApoB (Figure 3G) do not change after mid-term anti-TNF therapies with and without heterogeneity, respectively. ApoA1 (Figure 3F) tends to increase without heterogeneity. Mid-term anti-TNF therapies tend to decrease AI (Figure 3E), ApoB/ApoA1 ratio (Figure 3H), and $\mathrm{LDL} / \mathrm{HDL}$ ratio (Figure 3I). One study presented the ApoA 1 and $A p o B$ data in $\mathrm{mmol} / \mathrm{l}$ and was excluded from the meta-analyses (46).

Sensitivity analyses of TC and LDL indicate that one arm of the TEAR (TEAR1) study obviously influences the results of pooled MD (Supplementary Figures 4A,D) and removing the TEAR1 study from meta-analysis decreases the heterogeneity (Supplementary Figures 5A,B). When we 
TABLE 1 | Summary of the included studies.

\begin{tabular}{|c|c|c|c|c|c|c|c|c|c|c|}
\hline Study & Design & Patients & Female & RA duration ${ }^{\mathrm{a}}$ & DAS28 $^{\mathrm{b}}$ & $\mathrm{Age}^{\mathrm{C}}$ & Drug & Follow-up ${ }^{d}$ & Lipid $^{e}$ & Outcomes \\
\hline Masic et al. (20) & $\mathrm{RCT}$ & 86 & $61.6 \%$ & $83(43-132)^{\#}$ & $5.6 \pm 1.2$ & $53.4 \pm 15.7$ & ADA & $52 \mathrm{w}$ & $\mathrm{NF}$ & TC, TG, HDL, LDL \\
\hline Giles et al. (21) & $\mathrm{RCT}$ & 1542 & $78.0 \%$ & $7.2(3.1-4.6)$ & - & $61 \pm 8$ & ETN & $12,24,48 w$ & $\mathrm{NF}$ & TC, TG, HDL, LDL \\
\hline Corrado et al. (22) & cohort & 10 & $90 \%$ & - & $3.85 \pm 0.9$ & $49 \pm 13.06$ & ADA & $12,24 \mathrm{w}$ & $\mathrm{F}$ & TC, TG, HDL, LDL, Al, LDL/HDL \\
\hline Corrado et al. (22) & cohort & 11 & $91 \%$ & - & $4.05 \pm 0.9$ & $54.18 \pm 10.9$ & IFX & $12,24 w$ & $\mathrm{~F}$ & TC, TG, HDL, LDL, Al, LDL/HDL \\
\hline Corrado et al. (22) & cohort & 12 & $75 \%$ & - & $3.75 \pm 0.4$ & $53.42 \pm 5.75$ & ETN & $12,24 w$ & $\mathrm{~F}$ & TC, TG, HDL, LDL, Al, LDL/HDL \\
\hline Virone et al. (23) & $\mathrm{RCT}$ & 96 & $83.3 \%$ & - & $5.0(4.1-5.6)$ & $56.0(45.4-64.3)$ & Mixed & $24 w$ & $\mathrm{NF}$ & Apo A1 \\
\hline Bergstrom et al. (24) & cohort & 14 & $78.6 \%$ & $9.0(2.6-11.6)$ & $5.6 \pm 1.3$ & $63.7 \pm 8.9$ & ADA & $12 \mathrm{w}$ & $\mathrm{F}$ & TC, TG, HDL, LDL, LDL/HDL, Apo B, Apo A1, Apo B/A1 \\
\hline Rodriguez-Carrio et al. (25) & cohort & 13 & $92.3 \%$ & - & $5.08 \pm 1.93$ & $43(30-65)$ & Mixed & $12 \mathrm{w}$ & $\mathrm{F}$ & TG, HDL \\
\hline O'Neill et al. (26) & $\mathrm{RCT}$ & 11 & $72.7 \%$ & $6 m-3 y$ & $4.68 \pm 1.56$ & $61.30 \pm 11.05$ & IFX & $46 w$ & $\mathrm{~F}$ & TC, TG, HDL, LDL \\
\hline Gabay et al. (27) & $\mathrm{RCT}$ & 145 & $82 \%$ & $6.3 \pm 6.9$ & $6.8 \pm 0.9$ & $53.3 \pm 12.4$ & ADA & $8 w$ & $\mathrm{~F}$ & TC, TG, HDL, LDL, Al \\
\hline Charles-Schoeman et al. (28) & $\mathrm{RCT}$ & 141 & \multirow{2}{*}{$71.84 \%$} & \multirow{2}{*}{$3.30 \pm 5.70^{\star}$} & \multirow{2}{*}{$5.82 \pm 1.07$} & \multirow{2}{*}{$50.87 \pm 12.58$} & ETN & $24,48,102 w$ & NF & TC, HDL, LDL \\
\hline Charles-Schoeman et al. (28) & $\mathrm{RCT}$ & 104 & & & & & ETN & $24,78 w$ & NF & TC, HDL, LDL \\
\hline Bissell et al. (29) & $\mathrm{RCT}$ & 35 & $68 \%$ & $1.00(0.72-1.45)^{\star}$ & - & $52.3 \pm 13.0$ & IFX & $26,78 w$ & $\mathrm{~F}$ & HDL, LDL, Al, Apo B \\
\hline Deodhar et al. (30) & $\mathrm{RCT}$ & 98 & $82.7 \%$ & $7.4 \pm 8.1$ & $4.9 \pm 0.8$ & $55.5 \pm 12.8$ & ETN & $12 w$ & $\mathrm{~F}$ & TC, TG, HDL, LDL, Apo A1, Apo B \\
\hline Deodhar et al. (30) & $\mathrm{RCT}$ & 106 & $70.8 \%$ & $8.3 \pm 11.2$ & $4.9 \pm 0.7$ & $56.5 \pm 12.1$ & ETN & $12,24 w$ & $\mathrm{~F}$ & TC, TG, HDL, LDL, Apo A1, Apo B \\
\hline Ronda et al. (31) & cohort & 22 & $72.7 \%$ & $9(0.5-30)^{\star}$ & $5 \pm 5.8$ & $58 \pm 38.5$ & ADA & $6,26 w$ & - & TC, TG, HDL, LDL \\
\hline Chen et al. (32) & cohort & 32 & $87.5 \%$ & $13.4 \pm 6.6$ & $5.46 \pm 0.94$ & $53.5 \pm 12.6$ & ADA & $24 \mathrm{w}$ & $\mathrm{F}$ & TC, TG, HDL, LDL, Al \\
\hline Chen et al. (32) & cohort & 16 & $81.3 \%$ & $13.6 \pm 9.0$ & $5.48 \pm 0.98$ & $54.4 \pm 7.8$ & ETN & $24 w$ & $\mathrm{~F}$ & TC, TG, HDL, LDL, Al \\
\hline Rodriguez-Jimenez et al. (33) & cohort & 22 & $90.9 \%$ & $12.3 \pm 6.7$ & $6.2 \pm 0.8$ & $47.4 \pm 8.3$ & ETN & $4,24 w$ & - & TC, TG, HDL, LDL \\
\hline Cacciapaglia et al. (34) & cohort & 80 & $81.3 \%$ & $7 \pm 5$ & $4.7 \pm 1.6$ & $53 \pm 13$ & Mixed & $24 w, 52 w$ & - & TC, TG, HDL, LDL, Al \\
\hline Calvo Alen et al. (35) & cohort & 19 & $68 \%$ & $10.4 \pm 24.7$ & $5.5 \pm 1.2$ & $60.7 \pm 13.2$ & Mixed & $26 \mathrm{w}$ & - & TC \\
\hline Hjeltnes et al. (36) & cohort & 30 & $73 \%$ & $8 \pm 8$ & - & $58 \pm 8$ & Mixed & $6 w, 26 w$ & $\mathrm{~F}$ & TC, TG, HDL, LDL, Apo A1 \\
\hline Chen et al. (37) & cohort & 20 & $90 \%$ & $6.6 \pm 5.6$ & $>5.1$ & $53.8 \pm 11.8$ & ETN & $12,52 \mathrm{w}$ & $\mathrm{F}$ & TC, TG, HDL, LDL \\
\hline Sandoo et al. (38) & cohort & 23 & $65 \%$ & $11 \pm 11$ & - & $54 \pm 15$ & Mixed & $12 w$ & $\mathrm{~F}$ & TC, TG, HDL \\
\hline Sene et al. (39) & cohort & 16 & $81.3 \%$ & $9(2-39)$ & $6.31(5.28-7.94)$ & $48(27-69)$ & ETN & $26 w$ & $\mathrm{~F}$ & TC, TG, HDL, LDL \\
\hline Tam et al. (40) & $\mathrm{RCT}$ & 20 & $95 \%$ & $4.2(3.1-8.6)^{\star}$ & $5.1 \pm 0.7$ & $53(47-61)$ & IFX & $26 w$ & $\mathrm{~F}$ & TC, TG, HDL, LDL, Al \\
\hline Ajeganova et al. (41) & cohort & 60 & & & & & ETN & $12,26,52 w$ & - & Apo B, Apo A1, Apo B/A1 \\
\hline Ajeganova et al. (41) & cohort & 60 & $72.2 \%$ & $7(4-14)$ & $5.7 \pm 1.0$ & $56.2 \pm 12.4$ & IFX & & & \\
\hline Ajeganova et al. (41) & cohort & 42 & & & & & ADA & & & \\
\hline Kume et al. (42) & $\mathrm{RCT}$ & 21 & $85.7 \%$ & $11 \pm 5^{\star}$ & $5.17 \pm 1.5$ & $61 \pm 15$ & ETN & $24 w$ & $\mathrm{~F}$ & $\mathrm{TC}$ \\
\hline Kume et al. (42) & $\mathrm{RCT}$ & 21 & $85.7 \%$ & $9 \pm 5^{\star}$ & $5.34 \pm 1.4$ & $63 \pm 17$ & ADA & $24 w$ & $\mathrm{~F}$ & $\mathrm{TC}$ \\
\hline Jamnitski et al. (43) & cohort & 266 & $82 \%$ & $8(3-16)$ & $5.21 \pm 1.32$ & $52.8 \pm 12.7$ & ETN & $16,52 w$ & NF & TC, TG, HDL, LDL, Al, Apo B, Apo A1, Apo B/A1 \\
\hline Engvall et al. (44) & RCT & 18 & $72 \%$ & $4.9 \pm 3.4^{*}$ & $4.8(3.7-5.1)$ & $56.0(42.0-73.0)$ & IFX & $91 \mathrm{w}$ & - & Apo A1, Apo B, Apo B/A1 \\
\hline Derdemezis et al. (45) & cohort & 30 & $100 \%$ & $12.2 \pm 6.7$ & $4.9 \pm 1.3$ & $51.8 \pm 14.4$ & IFX & $26 \mathrm{w}$ & $\mathrm{F}$ & TC, TG, HDL, LDL \\
\hline Wijbrandts et al. (46) & cohort & 50 & $76 \%$ & $4.9(2.8-12.1)$ & $5.6 \pm 1.1$ & $51 \pm 13$ & ADA & $16 w, 52 w$ & $\mathrm{~F}$ & TC, TG, HDL, LDL, Al, Apo B/A1 \\
\hline
\end{tabular}


TABLE 1 | Continued

\begin{tabular}{|c|c|c|c|c|c|c|c|c|c|c|}
\hline Study & Design & Patients & Female & RA duration ${ }^{a}$ & DAS28 ${ }^{\mathrm{b}}$ & $\mathrm{Age}^{\mathrm{c}}$ & Drug & Follow-up ${ }^{d}$ & Lipid $^{e}$ & Outcomes \\
\hline Popa et al. (47) & cohort & 45 & $70 \%$ & $7.9 \pm 6.0$ & $5.26 \pm 1.24$ & $56 \pm 11$ & IFX & $2,26 \mathrm{w}$ & $\mathrm{F}$ & TC, TG, HDL, LDL, Al, LDL/HDL, Apo A1 \\
\hline Soubrier et al. (48) & cohort & 29 & $89.7 \%$ & - & $5.19 \pm 0.90$ & $57.4 \pm 10.6$ & Mixed & $14 w$ & $\mathrm{~F}$ & TC, TG, HDL, LDL, Al, Apo B, Apo A1, Apo B/A1 \\
\hline Nishida et al. (49) & cohort & 97 & $86.6 \%$ & $8.5 \pm 1.5$ & mean: 5.4 & $54.2 \pm 12.6$ & IFX & $52 w$ & - & $\mathrm{TC}, \mathrm{HDL}$ \\
\hline Bosello et al. (50) & cohort & 10 & $90 \%$ & $12.80 \pm 9.04$ & $6.66 \pm 1.00$ & $53.10 \pm 7.79$ & IFX & $6,14 w$ & $\mathrm{~F}$ & TC, TG, HDL \\
\hline Tam et al. (51) & cohort & 19 & $100 \%$ & $11 \pm 7$ & $5.31 \pm 1.06$ & $49 \pm 10$ & IFX & $6,14 w$ & $\mathrm{~F}$ & TC, TG, HDL, LDL, Al, Apo B, LDL/HDL \\
\hline Popa et al. (52) & cohort & 55 & $72.7 \%$ & $9 \pm 7$ & $5.26 \pm 1.25$ & $56 \pm 11$ & IFX & $2,26,52 w$ & $\mathrm{~F}$ & TC, TG, HDL, LDL, Al, LDL/HDL, Apo B, Apo A1 \\
\hline Peters et al. (53) & cohort & 80 & $77.5 \%$ & $10(0-59)$ & 5.7 & $56 \pm 14$ & IFX & $6,22,48 w$ & NF & TC, TG, HDL, Al, Apo A1, Apo B, Apo B/A1 \\
\hline Oguz et al. (54) & cohort & 7 & $85.7 \%$ & 6.8 & $5.8 \pm 0.9$ & $44.6 \pm 12.3$ & IFX & mean: $42 w$ & $\mathrm{~F}$ & TG, HDL, TG/HDL \\
\hline Komai et al. (55) & cohort & 15 & $86.7 \%$ & $10.0 \pm 2.3$ & $5.07 \pm 0.77$ & $50 \pm 3$ & IFX & $6,26,52 w$ & - & TC, TG, HDL, LDL \\
\hline Seriolo et al. (56) & cohort & 34 & $100 \%$ & $14 \pm 9$ & $6.9 \pm 2.1$ & $51.6 \pm 7.9$ & Mixed & $16 w, 24 w$ & $\mathrm{~F}$ & TC, TG, HDL, Al \\
\hline Dahlqvist et al. (57) & cohort & 52 & $78.8 \%$ & $14.1 \pm 8.6$ & $5.9 \pm 0.72$ & $54.6 \pm 12.5$ & IFX & $12,26,52 w$ & - & TC, HDL, Al, LDL/HDL \\
\hline Allanore et al. (58) & cohort & 56 & $91 \%$ & $13 \pm 7$ & - & $52 \pm 14$ & IFX & $6 w, 30 w$ & $\mathrm{~F}$ & TC, TG, HDL, LDL, Al, LDL/HDL \\
\hline Gonzalez-Juanatey et al. (59) & cohort & 8 & $87.5 \%$ & $20(7-29)$ & $5.5 \pm 1.3$ & $51(24-74)$ & ADA & $12 w$ & $\mathrm{~F}$ & TC, HDL, Al \\
\hline Spanakis et al. (60) & cohort & 24 & $70.8 \%$ & $14.1 \pm 7.2^{*}$ & $6.9 \pm 1.3$ & $62.7 \pm 10.1$ & IFX & $12,26 \mathrm{w}$ & $\mathrm{F}$ & $\mathrm{TC}, \mathrm{HDL}$ \\
\hline Popa et al. (61) & cohort & 33 & - & - & $5.24 \pm 1.05$ & - & ADA & $2 \mathrm{w}$ & $\mathrm{F}$ & TC, TG, HDL, LDL, Al, LDL/HDL \\
\hline Vis et al. (62) & cohort & 69 & $80 \%$ & $12(0-59)$ & $5.9 \pm 1.4$ & $58(24-80)$ & IFX & $6 \mathrm{w}$ & NF & $\mathrm{TC}, \mathrm{HDL}, \mathrm{Al}$ \\
\hline Irace et al. (63) & cohort & 10 & $60 \%$ & $7 \pm 2$ & $3.4 \pm 1.3$ & $46 \pm 12$ & IFX & $6 w$ & $\mathrm{~F}$ & TC, TG, HDL, Apo A1, Apo B \\
\hline
\end{tabular}

${ }^{a}$ Data are mean $\pm S D$, median [interquartile range (IQR)], range, median (range), or mean (range) in years, unless otherwise specified; *in months; ${ }^{\#}$ in days. ${ }^{b}$ Data are mean $\pm S D$, mean, median, median (IQR), or median (range), unless otherwise specified; if both Disease Activity Score-28-C-reactive protein (DAS28-CRP) and DAS-28-erythrocyte sedimentation rate (DAS28-ESR) are provided, DAS28-ESR is presented. ${ }^{\circ}$ Data are mean \pm SD, median (IQR), or median (range) in years unless otherwise specified. ${ }^{d}$ When follow-up duration is not presented as weeks, convert it to weeks by using: 1 month $=4$ weeks, 3 months $=12$ weeks, 6 months $=26$ weeks, and 1 year $=52$ weeks; only time points that are included in the meta-analysis are presented. ${ }^{e} \mathrm{~F}=$ lipids measured by using the fasting blood samples; $N F=$ lipids measured by using the non-fasting blood samples. 
TABLE 2 | Summary of the meta-analyses of changes in lipid profile.

\begin{tabular}{lcccc}
\hline & $\begin{array}{c}\text { Number } \\
\text { of study }\end{array}$ & $\begin{array}{c}\text { Number of } \\
\text { patients }\end{array}$ & WMD (95\% Cl) & $\begin{array}{c}\text { Heterogeneity } \\
\boldsymbol{I}^{2}, \boldsymbol{p} \text {-value }\end{array}$ \\
\hline Short-term & & & & \\
TC (mmol/l) & 26 & 2530 & $0.14(0.08,0.19)$ & $15.8 \%, 0.236$ \\
TG (mmol/l) & 23 & 2390 & $0.03(-0.00,0.07)$ & $0.0 \%, 0.979$ \\
HDL (mmol/l) & 27 & 2542 & $0.11(0.07,0.15)$ & $51.8 \%, 0.001$ \\
LDL (mmol/l) & 18 & 2253 & $0.06(0.01,0.12)$ & $4.3 \%, 0.404$ \\
Al & 12 & 515 & $-0.12(-0.35,0.10)$ & $54.3 \%, 0.012$ \\
Apo A1 (g/l) & 11 & 600 & $0.07(0.04,0.10)$ & $0.0 \%, 0.590$ \\
Apo B (g/l) & 10 & 544 & $0.02(-0.01,0.05)$ & $0.0 \%, 0.651$ \\
Apo B/Apo A1 & 5 & 256 & $-0.02(-0.05,0.02)$ & $0.0 \%, 0.825$ \\
LDL/HDL & 10 & 307 & $-0.14(-0.30,0.01)$ & $43.1 \%, 0.071$ \\
mid-term & & & & \\
TC (mmol/l) & 30 & 2918 & $0.23(0.10,0.36)$ & $73.1 \%, 0.000$ \\
TG (mmol/l) & 23 & 2536 & $0.01(-0.03,0.04)$ & $14.0 \%, 0.270$ \\
HDL (mmol/l) & 29 & 2906 & $0.12(0.06,0.19)$ & $84.0 \%, 0.000$ \\
LDL (mmol/l) & 23 & 2692 & $0.06(-0.04,0.15)$ & $52.1 \%, 0.002$ \\
Al & 16 & 766 & $-0.12(-0.29,0.06)$ & $64.4 \%, 0.000$ \\
Apo A1 (g/l) & 11 & 869 & $0.03(-0.00,0.06)$ & $0.0 \%, 0.981$ \\
Apo B (g/l) & 10 & 752 & $0.00(-0.02,0.02)$ & $0.0 \%, 0.720$ \\
Apo B/Apo A1 & 7 & 587 & $-0.02(-0.05,0.00)$ & $0.0 \%, 0.940$ \\
LDL/HDL & 7 & 204 & $-0.28(-0.67,0.10)$ & $78.4 \%, 0.000$ \\
long-term & & & & \\
TC (mmol/l) & 14 & 2639 & $0.26(0.02,0.49)$ & $86.9 \%, 0.000$ \\
TG (mmo//) & 11 & 2252 & $0.03(-0.05,0.11)$ & $47.0 \%, 0.042$ \\
HDL (mmol/l) & 17 & 2695 & $0.11(0.04,0.19)$ & $85.4 \%, 0.000$ \\
LDL (mmo//) & 12 & 2445 & $0.10(-0.05,0.24)$ & $69.2 \%, 0.000$ \\
Al & 7 & 594 & $0.03(-0.11,0.17)$ & $19.1 \%, 0.284$ \\
Apo A1 (g/l) & 7 & 581 & $0.03(-0.01,0.07)$ & $25.5 \%, 0.234$ \\
Apo B (g/l) & 8 & 616 & $0.01(-0.02,0.03)$ & $0.0 \%, 0.877$ \\
Apo B/Apo A1 & 7 & 576 & $-0.02(-0.04,0.01)$ & $0.0 \%, 0.789$ \\
LDL/HDL & 3 & 163 & $0.11(-0.12,0.34)$ & $0.0 \%, 0.430$ \\
\hline & & & & \\
\hline
\end{tabular}

checked the characteristics of the TEAR1 study $(28,64)$, we found a high dropout rate (31.1\%) (Supplementary Table 3). Again, sensitivity analysis of TG reveals that the ENTRACTE trial significantly affects the variation, but not the pooled MD results (Supplementary Figure 4B). Sensitivity analyses of HDL, AI, ApoA1, ApoB, ApoB/ApoA1 ratio, and LDL/HDL ratio show that these indexes are not affected by removing any of the included studies (Supplementary Figures 4C,E-I).

The funnel plot, Begg's test, and Egger's test show that the pooled MD of mid-term changes in blood TC, TG, HDL, LDL, AI, ApoA1, and ApoB are at low risk of publication bias (Supplementary Figures 6A-G).

\section{Long-Term Changes in Lipid Profile}

Long-term changes in lipid profile after anti-TNF treatments are summarized in Table 2 and the forest plots are shown in Figure 4. Long-term anti-TNF treatments are associated with a significant increase in TC (Figure 4A) and HDL (Figure 4C) with heterogeneity. TG (Figure 4B) and LDL (Figure 4D) do not change after long-term anti-TNF therapies with heterogeneity.
Long-term anti-TNF therapies do not change AI, ApoA1, ApoB, ApoB/ApoA1 ratio, and $\mathrm{LDL} / \mathrm{HDL}$ ratio without heterogeneity (Figures 4E-I). One study presented the ApoA1 and ApoB data in $\mathrm{mmol} / \mathrm{l}$ and was excluded from the meta-analyses (46).

Sensitivity analysis of TG indicates that the study by Popa (Popa-2007) (52) obviously influences the results of pooled MD (Supplementary Figure 7B) and remove it from meta-analysis decreases the heterogeneity (Supplementary Figure 8A). The heterogeneity of the Popa2007 study may be due to a high dropout rate (43.6\%) in the study (Supplementary Table 3). Again, the TEAR1 study influences the results of pooled MD for LDL (Supplementary Figure 7D) and remove it from meta-analysis decreases the heterogeneity (Supplementary Figure 8B). Sensitivity analyses of TC, HDL, AI, ApoA1, ApoB, ApoB/ApoA1 ratio, and LDL/HDL ratio show that these lipids are not affected by removing any included studies (Supplementary Figures 7A-I).

The funnel plot, Begg's test, and Egger's test show that the pooled MD of mid-term changes in blood TC, TG, HDL, and LDL are at low risk of publication bias (Supplementary Figures 9A-D).

\section{Subgroup Analyses and Meta-Regression}

Subgroup analyses of changes in all the lipid profiles in the short-, mid, and long-term are summarized in Supplementary Tables 4-12, where meta-regression was also presented for the lipids with more than 10 studies available for analysis.

We found that RA duration may contribute to the heterogeneity of various changes of the lipids. Subgroup analyses show that meta-analysis of lipid changes in the patients with RA duration $\geq 6$ months is usually with decreased heterogeneity compared to the total population. For the patients with disease duration for more than 6 months, mid-term and long-term TNF inhibition are associated with increased HDL (MD: +0.03 mmol/l for mid-term; MD: $+0.08 \mathrm{mmol} / \mathrm{l}$ for longterm) without heterogeneity (Supplementary Table 6); midterm and long-term TNF inhibition is not associated with LDL change without heterogeneity (Supplementary Table 7); short-term and mid-term TNF inhibition is not associated with AI change without heterogeneity (Supplementary Table 8). Meta-regression also shows that RA duration may significantly contribute to the heterogeneity $(p<0.05$ for HDL short and mid-term changes in Supplementary Table 6, for LDL mid-term change in Supplementary Table 7, and AI short and mid-term changes in Supplementary Table 8).

Subgroup analysis and meta-regression imply that IFX may be associated with a more short-term increase in TC (Supplementary Table 4). Meta-regression also indicates that baseline lipid levels may contribute to the heterogeneity for long-term TC change (Supplementary Table 4) and quality score may be a possible source of heterogeneity for long-term LDL change (Supplementary Table 7). Baseline DAS28, age of the patient, and different TNF inhibitors do not likely contribute to the heterogeneity in the current meta-analyses. 

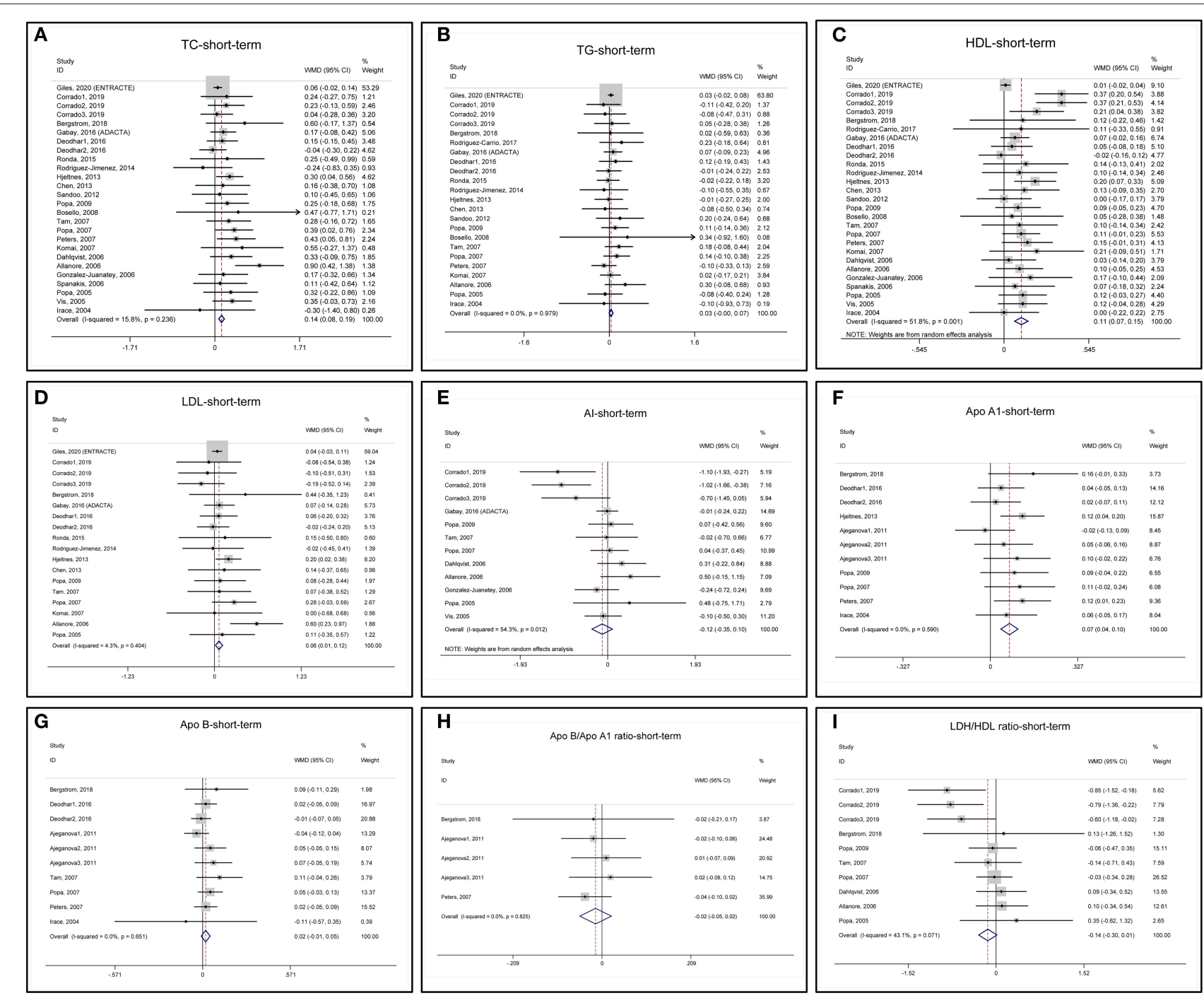

FIGURE 2 | Forest plots of meta-analyses of the short-term changes in (A) total cholesterol (TC), (B) triglyceride (TG), (C) high-density lipoprotein (HDL), (D) low-density lipoprotein (LDL), (E) atherogenic index (Al), (F) ApoA1, (G) ApoB, (H) ApoB/ApoA1 ratio, and (I) LDL/HDL ratio.

\section{DISCUSSION}

The current meta-analysis investigates the changes in blood lipid profile after short-term (0-12 weeks), mid-term (13-26 weeks), and long-term (>26 weeks) anti-TNF therapies in patients with RA. This study is important for some reasons. First, it adds meta-analysis of the lipid changes following long-term anti-TNF treatments based on sufficient studies, which provides evidence to evaluate the possible roles of lipid alterations in the favorable CVDs effects of TNF blockade in RA. Second, this study is a stateof-art meta-analysis that systematically analyzes apolipoproteins and several atherogenic lipid ratios including AI, ApoB/ApoA1, and LDL/HDL, which gives an overall view of the lipid changes, since previous studies have shown simultaneous elevations in both "proatherogenic" and "antiatherogenic" lipids. Third, the comprehensive subgroup analysis in this study provides insights into factors that may impact lipid profile after antiTNF therapies, which are not provided by previous studies. Finally, we observed consistent increases in TC and HDL as the previous meta-analysis (10), but we also come to the new conclusion of TG and LDL, the changes of which varied in previous studies (65).

The mid and long-term increase in TC after TNF blockade (MD: $+0.23,+0.26 \mathrm{mmol} / \mathrm{l}$ in the mid and long-term, respectively) is primarily possible due to an increase in the antiatherogenic HDL (MD: $+0.12,+0.11 \mathrm{mmol} / \mathrm{l}$ in the mid and long-term, respectively), as we found no significant changes in TG, atherogenic lipids (LDL and ApoB), and atherogenic indexes (TC/HDL, ApoB/ApoA1, and LDL/HDL) after mid and longterm TNF inhibition. In general, lipid profile changes toward an atheroprotective direction. A previous meta-analysis showed a similar increase in TC and HDL in the short- and mid-term after 


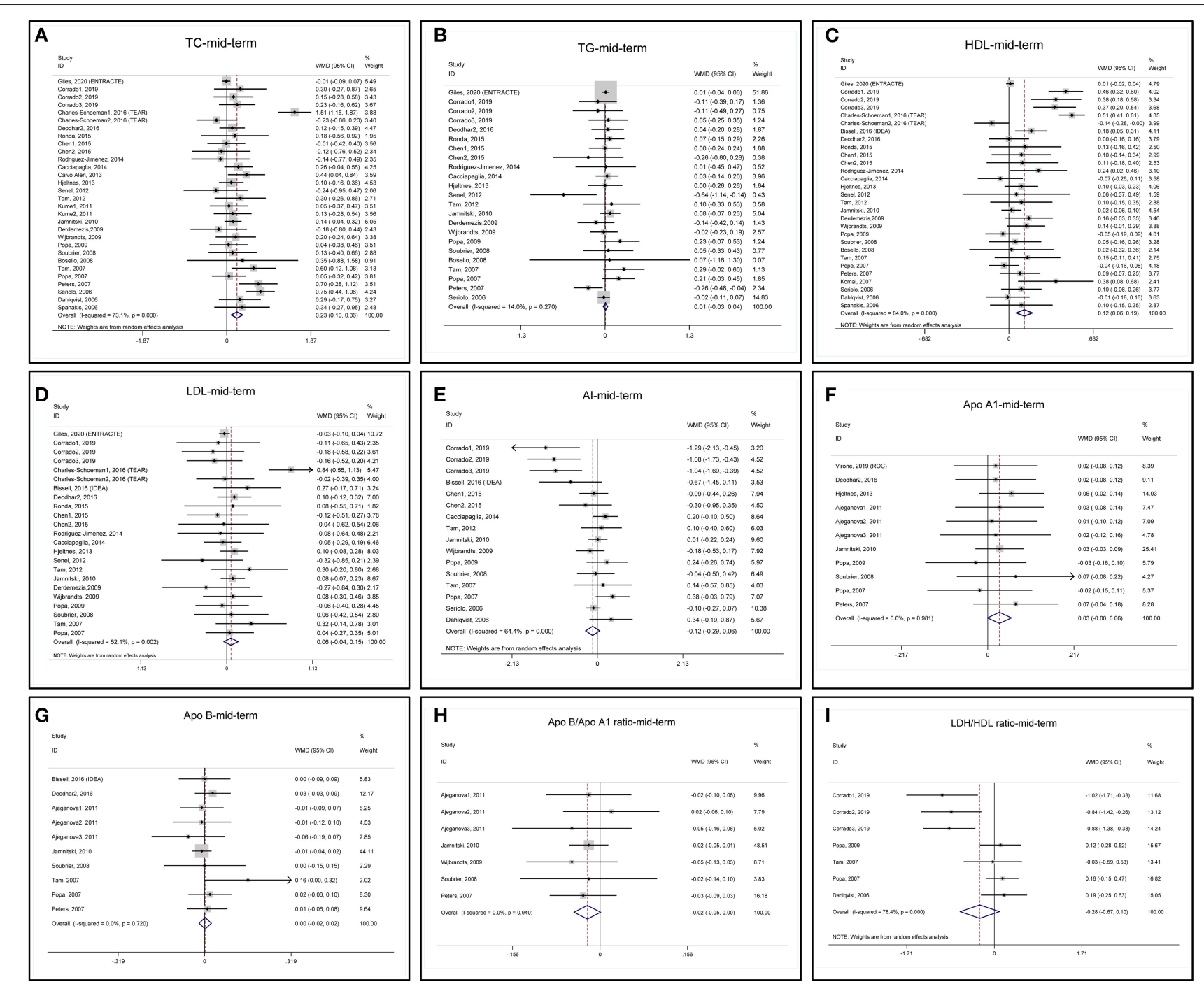

FIGURE 3 | Forest plots of meta-analyses of the mid-term changes in (A) TC, (B) TG, (C) HDL, (D) LDL, (E) Al, (F) ApoA1, (G) ApoB, (H) ApoB/ApoA1 ratio, and (I) LDL/HDL ratio.

TNF inhibition, but it did not evaluate long-term changes of the lipids (9). According to the study by Daien et al. (10), they also indicated an association between TNF inhibition and elevated HDL, elevated TC, unchanged LDL, and unchanged AI in the long-term, but it mostly included studies that using IFX, which was the prior choice of TNF inhibition at that time. We have included more studies with ADA and ETN published in recent years. Different from our results, Daien et al. found that TG level increased and ApoB/ApoA decreased after long-term inhibition, but their results were based on a very small population.

The mechanisms behind the increase of TC and HDL upon TNF inhibition are unclear. Basic researches have revealed a complex regulation between TNF and lipid metabolism, involving regulations in both hepatocytes, macrophages, and adipocytes, which need further verification in human (66). Previous evidence indicates that reduced lipid catabolism after inflammation inhibition may result in elevations in lipid levels (67).

In the current meta-analysis, to detect the possible confounding effects from the use of corticosteroids, cDMARDs, and lipid-lowering drugs (e.g., statins) that may affect the blood lipids, we included six items toward the use of these drugs in quality assessment (Supplementary Table 3), where we evaluated whether those treatments were listed at the baseline and controlled during the treatment periods. Those studies with descriptions such as "corticosteroids/MTX/statins use was stable during the study period" were considered with low risk. We also listed the baseline use of those drugs for each study in Supplementary Table 1. In this way, we try to control the confounding risk of corticosteroids/MTX/statins use within studies. However, we still cannot completely control the "interstudy" confounding risk from corticosteroids/MTX/statins 

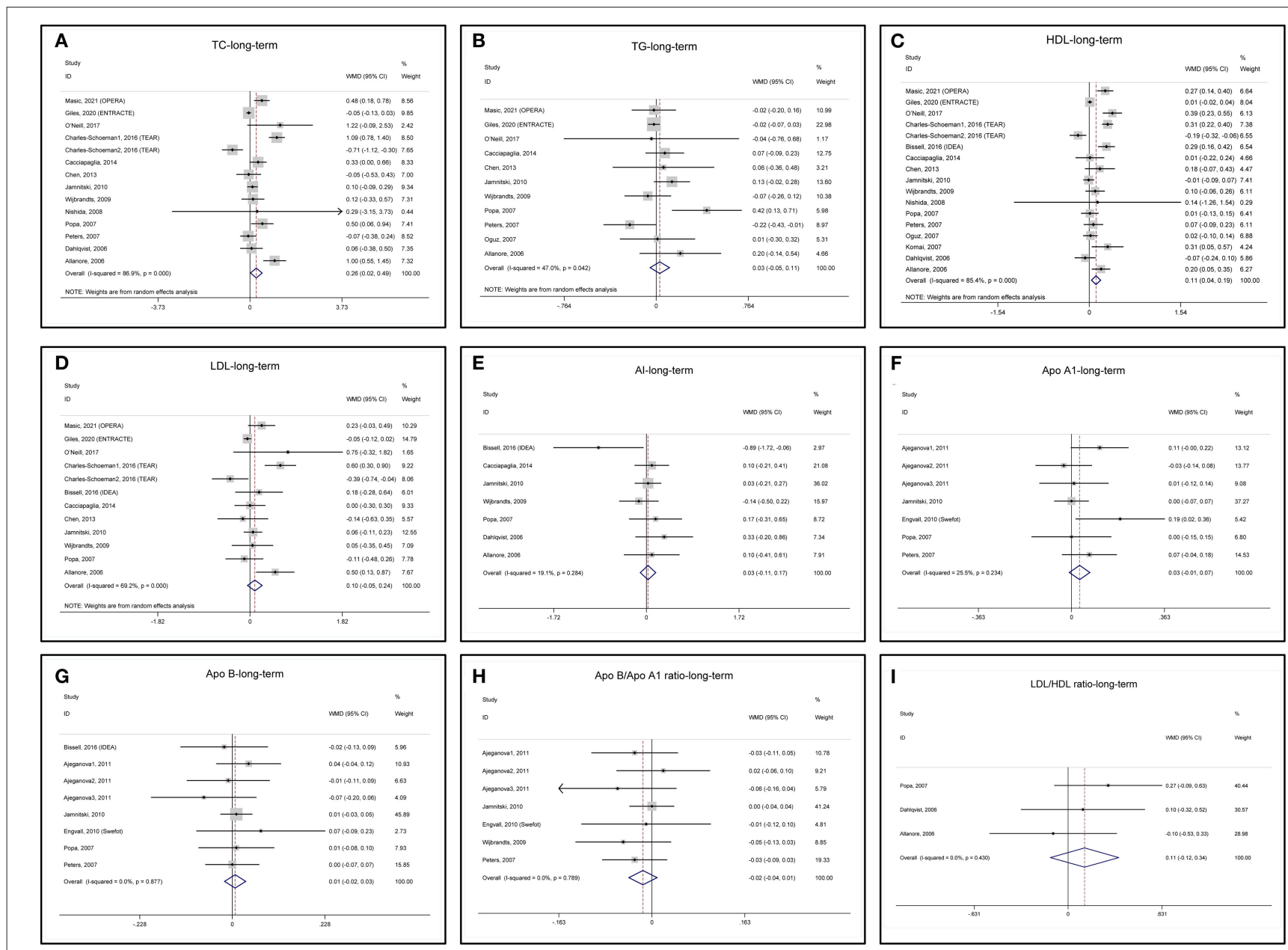

FIGURE 4 | Forest plots of meta-analyses of the long-term changes in (A) TC, (B) TG, (C) HDL, (D) LDL, (E) Al, (F) ApoA1, (G) ApoB, (H) ApoB/ApoA1 ratio, and (I) LDL/HDL ratio.

use. As shown in Table 2, although MTX was the most frequently used cDMARDs, prednisolone and prednisone were the most frequently used steroids, and statins were the most frequently used lipid-lowering therapies, the dosage and the percentage of drug use among different studies varied slightly, which may cause heterogeneity among studies. In this study, we do not include unpublished data, which are usually with smaller sample sizes and uncontrolled bias due to lack of peer view (68).

We found that the meta-analyses for lipid changes in the mid and long-term are usually with heterogeneity, which may come from different RA duration as indicated by subgroup analysis and meta-regression. When checking the concomitant uses of corticosteroids, cDMARDs, and lipid-lowering drugs (Supplementary Table 1) in studies, we found that a smaller portion of the patients was treated with those drugs or treated with lower dosages in the RA duration $<6$ months subgroup. This may be because that the patients with early RA suffer from less severe diseases. We also observed that the information of statin use during the TNF inhibition treatment period was usually unavailable for the studies that included the patients with early RA (see Supplementary Table 3, the "representativeness of study population" item, where the " 1 " superscript indicates early RA), which may be because that most of these studies were not focused on investigating the lipid changes (see the "designed to evaluate lipid levels" item). Only a small portion of studies and patients are with disease duration $<6$ months possibly because that treatment-naïve patients have more choices other than TNF inhibition. Hence, it should be very cautious to interpret the results for early RA, and more studies in the future are needed.

For both HDL changes in the mid-term and long-term, we observed that meta-regression indicated marginal $p$ values ( $p=0.054$ and $p=0.071$, respectively) for baseline HDL (Supplementary Table 6). When checking baseline HDL levels for each included study, we found a very broad distribution of baseline HDL levels from 0.86 to $1.91 \mathrm{mmol} / \mathrm{L}$ (even baseline TC levels among the included studies only vary between around 4.3 and $6.4 \mathrm{mmol} / \mathrm{L}$ ). We consider this huge difference (more than double) in baseline HDL levels that may account partially for the heterogeneity for changes in HDL, no matter in the short-, 
mid-, or long-term. Hence, caution is needed when interpreting these results.

Besides the quantitative changes in HDL after TNF inhibition, the functional changes of HDL add more complexity to the issue. By promoting cholesterol efflux, reducing inflammation, ameliorating oxidation, and improving endothelial function, HDL protects against atherosclerosis. As shown in this metaanalysis, the consistent increase in HDL in all the periods may partially account for the reduced CVDs risk in the patients with RA accepting anti-TNF treatments. However, improvements in the functions of the HDL followed by a relief of inflammation may also contribute to the CVD benefits of TNF inhibitors.

In the inflammatory state, proinflammatory cytokines such as TNF and interleukin-6 (IL-6) significantly induce the hepatic expression of apolipoprotein serum amyloid A (SAA), which replaces ApoA1 on HDL and results in SAA-rich HDL. SAArich HDL was eliminated from plasma more rapidly than Apo A1-HDL (69) and showed decreased ability to induce endothelial nitric oxide (NO) production, inhibit endothelial reactive oxygen species (ROS) production, decrease inflammation, and induce cholesterol efflux $(70,71)$. When SAA is high, HDL cholesterol (HDL-C) inversely correlates with all-cause and cardiovascular mortality (70). In RA, HDL-associated SAA was upregulated (72) and TNF inhibition was correlated with reduced HDL-associated SAA level (27), especially in those responders. The most recent study shows that a $22 \%$ increase in anti-inflammation of HDL in the endothelial cells is associated with a $23 \%$ reduction in 10-year cardiovascular event risk. The beneficial effect is independent of the HDL level or cholesterol efflux capacity (CEC) of HDL (73). Since SAA-rich HDL exhibits impaired antiinflammation capacity, anti-TNF therapies may decrease CVDs risk by correcting the impaired anti-inflammation function of HDL in RA.

Inflammation also impairs the expression and activity of paraoxonase 1 (PON1), the major component that accounts for the antioxidative capacity of HDL. PON1 hydrolyzes a wide range of substrates including atherogenic lipid peroxides, thus exerting atheroprotective roles. The PON1 single nucleotide polymorphism (SNP) Q192R greatly influences PON1 activity. Individuals carrying the RR allele, which associates with higher PON1 activity, had lower systemic oxidative stress and CVDs risk (74). In the patients with RA, the RR genotype correlated with decreased risk of carotid plaque (75). With respect to the general population, PON1 activity was significantly decreased, while oxidative metabolites were increased in the patients with RA, especially in patients with high disease activity (76). In mouse inflammatory arthritis models, overexpression of human PON1 decreased bioactive lipid mediators and ameliorates arthritis (77). TNF and ROS interact reciprocally in a positive feedback loop, exaggerating the inflammatory and oxidative stress in inflammatory diseases. Besides, TNF decreased PON1 expression in HepG2 cells, a hepatoma cell line (78), implying a therapeutic potential to inhibit oxidative stress by TNF inhibition. Indeed, Popa et al. proved that a 6-month TNF blockade by IFX increased PON1 activity and antioxidative capacity of HDL in the patients with RA, which correlated with a decrease in erythrocyte sedimentation rate
(ESR) (47). A genome-wide association scan also identified that an SNP locus that includes the PON1 gene correlates with response to anti-TNF therapies in the patients with RA, indicating a role of PON1 in disease amelioration following TNF inhibition (79).

In contrast to PON1, myeloperoxidase (MPO), a peroxidase enzyme, facilitates ROS production and oxidizes ApoA1 on $\mathrm{HDL}$, leading to dysfunctional HDL and contributing to atherosclerosis. Induced by oxidative stress and inflammation, MPO promoted the development of arthritis in an experimental mouse model (80). In the patients with RA, MPO/PON1 ratio was elevated, positively correlated with DAS28, and higher in the patients with a history of CVDs compared to the patients without a history of CVDs (81). Higher plasma MPO activity and increased MPO-oxidized HDL in RA are also associated with decreased antioxidant and cholesterol efflux capacity of HDL $(82,83)$. All these results imply that amelioration of inflammation in RA may decrease MPO and improve the functions of HDL.

Cholesterol efflux capacity inversely correlates with CVDs risk in the general population, independent of HDL level. HDL from the patients with RA exhibited impaired CEC (83) and a higher CEC was correlated with a lower presence of carotid plaque in the patients with RA (84). Moreover, CEC was negatively related to disease activity in RA and TNF inhibition partially restored CEC (85). TNF attenuated CEC via suppressing the expression of $\mathrm{ABCA} 1$, the primary molecule that mediates cholesterol efflux to ApoA1 (86). Furthermore, TNF reduced the expression of lecithin-cholesterol acyltransferase (LCAT) and cholesteryl ester transfer protein (CETP) $(87,88)$, two enzymes in HDL that facilitate cholesterol efflux and were decreased in RA $(67,89)$. The above evidence illuminates the potential of TNF inhibition to restore the CEC of HDL in RA, either by directly blocking TNF signaling or by ameliorating systemic inflammation. Indeed, reduction in high-sensitivity C-reactive protein (hs-CRP) correlates with improved CEC in RA (85). In this study, we found a significant increase in ApoAI, which may also promote cholesterol efflux. However, in a small cohort of the patients with RA, 1-year treatment of IFX failed to improve CEC in HDL significantly (26). Another small cohort study also found a non-significant increase in CEC in the patients with CEC after a 6-month treatment of ADA (31). Further studies including a larger number of patients are still needed to evaluate the effect of anti-TNF therapies on CEC in HDL.

Cardiovascular disease development in RA is partially due to endothelial dysfunction caused by multiple factors including the elevated proinflammatory cytokines (such as TNF). A meta-analysis including 20 studies demonstrates that anti-TNF treatment improves endothelial function in RA (90). HDL ameliorates endothelium injury in atherosclerosis by promoting nitric oxide (NO) production, inhibiting inflammation, apoptosis, and thrombosis, and facilitating endothelial repair. The beneficial effects of anti-TNF therapies at least partially come from improved HDL function. O'Neill et al. revealed an elevated endothelial NO bioavailability and reduced superoxide production by HDL isolated from the patients with RA who received a 2-year IFX treatment compared to HDL from those receiving placebo (26). Still, more evidence is needed. 
Following TNF inhibition, the increase in HDL and ApoA1 is usually more significant in those responsive to TNF blockade $(24,52,60,62)$, corresponding to the fact that those responders gain more prominent CVDs benefits (8), suggesting a role of decreased systemic inflammation following anti-TNF therapies in the observed CVDs benefits. Currently, we cannot analyze the association between treatment response and lipid changes due to insufficient data. In this meta-analysis, the increase in HDL in the long-term $(+0.11 \mathrm{mmol} / \mathrm{l})$ seems too minor to exert beneficial cardiovascular effects. However, based on four large prospective cohorts, a $0.026 \mathrm{mmol} / \mathrm{l}(1 \mathrm{mg} / \mathrm{dl})$ increment in HDL correlated with a $2-3 \%$ reduction in the risk of coronary heart disease (91). Together with improved HDL functions after antiTNF treatments $(27,47,85)$, we propose that improvements in both "quantity" and "quality" of HDL contribute to the observed cardiovascular benefits of TNF inhibition in the patients with RA. However, further evidence is needed to support that improved HDL functions after TNF inhibition promotes the reduced CVDs risk in the RA population. Alterations in LDL subgroups and modifications may also help to lower CVDs risk (92).

This study encompasses some limitations. The effects of golimumab or certolizumab on lipids are not investigated in our meta-analysis due to insufficient data. We did not include lipoprotein(a) $[\mathrm{Lp}(\mathrm{a})]$ data into the meta-analysis because few studies reported $\mathrm{Lp}(\mathrm{a})$ and a mixed presentation of $\mathrm{Lp}(\mathrm{a})$ in either $\mathrm{mmol} / \mathrm{l}$ or $\mathrm{mg} / \mathrm{dl}$ or logarithmic or original form in the different studies. The DAS28, we collected, is a mixture of results based on either CRP or erythrocyte sedimentation rate (ESR). However, we used a threshold of 5.1 (which is generally considered for DAS28-ESR) to differentiate the patients with high disease activity. We cannot explain the heterogeneity for long-term change in TC after TNF inhibition (though meta-regression indicated a marginal $p=0.063$ for quality score, see Supplementary Table 4). One possibility is that other confounding factors may come up during the long-term treatment (e.g., drug use for complications of RA). Thus, caution is needed when interpreting the results.

In conclusion, the current meta-analysis shows that although anti-TNF therapies were associated with a significant increase

\section{REFERENCES}

1. Tardif JC, Kouz S, Waters DD, Bertrand OF, Diaz R, Maggioni AP, et al. Efficacy and safety of low-dose colchicine after myocardial infarction. $N$ Engl J Med. (2019) 381:2497-505. doi: 10.1056/NEJMoa1912388

2. Nidorf SM, Fiolet ATL, Mosterd A, Eikelboom JW, Schut A, Opstal TSJ, et al. Colchicine in patients with chronic coronary disease. N Engl J Med. (2020) 383:1838-47. doi: 10.1056/NEJMoa2021372

3. Ridker PM, Everett BM, Thuren T, MacFadyen JG, Chang WH, Ballantyne C, et al. Antiinflammatory therapy with canakinumab for atherosclerotic disease. N Engl J Med. (2017) 377:1119-31. doi: 10.1056/NEJMoa1707914

4. Myasoedova E, Crowson CS, Kremers HM, Roger VL, Fitz-Gibbon PD, Therneau TM, et al. Lipid paradox in rheumatoid arthritis: the impact of serum lipid measures and systemic inflammation on the risk of cardiovascular disease. Ann Rheum Dis. (2011) 70:482-7. doi: 10.1136/ard.2010.135871

5. Micha R, Imamura F. Wyler von Ballmoos M, Solomon DH, Hernan MA, Ridker PM, et al. Systematic review and meta-analysis of methotrexate in blood TC in the long-term in RA, atherogenic lipids (LDL and $A p o B$ ) and atherogenic indexes (AI, ApoB/ApoA1, and LDL/HDL) do not increase after long-term TNF blockade. HDL mostly contributes to the increased TC. Together with evidence that inflammation impairs HDL functions and inflammation reduction is associated with improved $\mathrm{HDL}$ functions, it is likely that improvements in HDL quantity and quality at least partially contribute to the reduced CVDs risk by TNF inhibition. Our findings add to evidence that systemic inflammation inhibition may exert a favorable alteration in lipid profile and HDL function in the patients with a highly inflammatory state, thus potentiating to reduce the CVD risk in those patients. However, direct evidence is still required in the future.

\section{DATA AVAILABILITY STATEMENT}

The raw data supporting the conclusions of this article will be made available by the authors, without undue reservation.

\section{AUTHOR CONTRIBUTIONS}

YL and DP come up with the concept and design of the study. YL, XR, SW, CY, and QM performed the data collection. YL performed the statistical analysis, did the interpretation, and drafted the manuscript. DP revised the manuscript. All the authors contributed to the article and approved the submitted version.

\section{FUNDING}

This study was supported by grants from the National Natural Science Foundation of China (No. 81870336).

\section{SUPPLEMENTARY MATERIAL}

The Supplementary Material for this article can be found online at: https://www.frontiersin.org/articles/10.3389/fcvm. 2021.765749/full\#supplementary-material use and risk of cardiovascular disease. Am J Cardiol. (2011) 108:136270. doi: 10.1016/j.amjcard.2011.06.054

6. Sharma TS, Wasko MC, Tang X, Vedamurthy D, Yan X, Cote J, et al. Hydroxychloroquine use is associated with decreased incident cardiovascular events in rheumatoid arthritis patients. J Am Heart Assoc. (2016) 5:e002867. doi: 10.1161/JAHA.115.002867

7. Amezaga Urruela M, Suarez-Almazor ME. Lipid paradox in rheumatoid arthritis: changes with rheumatoid arthritis therapies. Curr Rheumatol Rep. (2012) 14:428-37. doi: 10.1007/s11926-012-0269-z

8. Dixon WG, Watson KD, Lunt M, Hyrich KL. British Society for Rheumatology Biologics Register Control Centre C, Silman AJ, et al. Reduction in the incidence of myocardial infarction in patients with rheumatoid arthritis who respond to anti-tumor necrosis factor alpha therapy: results from the British Society for Rheumatology Biologics Register. Arthritis Rheum. (2007) 56:2905-12. doi: 10.1002/art.22809

9. van Sijl AM, Peters MJ, Knol DL, de Vet RH, Sattar N, Dijkmans $\mathrm{BA}$, et al. The effect of TNF-alpha blocking therapy on lipid levels in 
rheumatoid arthritis: a meta-analysis. Semin Arthritis Rheum. (2011) 41:393400. doi: 10.1016/j.semarthrit.2011.04.003

10. Daien CI, Duny Y, Barnetche T, Daures JP, Combe B, Morel J. Effect of TNF inhibitors on lipid profile in rheumatoid arthritis: a systematic review with meta-analysis. Ann Rheum Dis. (2012) 71:8628. doi: 10.1136/annrheumdis-2011-201148

11. Di Minno MN, Ambrosino P, Peluso R, Di Minno A, Lupoli R, Dentali F, et al. Lipid profile changes in patients with rheumatic diseases receiving a treatment with TNF-alpha blockers: a meta-analysis of prospective studies. Ann Med. (2014) 46:73-83. doi: 10.3109/07853890.2013. 874661

12. Higgins JPT, Altman DG, Gøtzsche PC, Jüni P, Moher D, Oxman AD, et al. The Cochrane Collaboration's tool for assessing risk of bias in randomised trials. BMJ. (2011) 343:d5928. doi: 10.1136/bmj.d5928

13. Wells G, Shea B, O'Connell D, Peterson J, Welch, Losos M, et al. The newcastleottawa scale (NOS) for assessing the quality of nonrandomised studies in meta-analyses. (2014).

14. Slim K, Nini E, Forestier D, Kwiatkowski F, Panis Y, Chipponi J. Methodological index for non-randomized studies (minors): development and validation of a new instrument. ANZ J Surg. (2003) 73:7126. doi: 10.1046/j.1445-2197.2003.02748.x

15. Whiting PF, Weswood ME, Rutjes AWS, Reitsma JB, Bossuyt PNM, Kleijnen J. Evaluation of QUADAS, a tool for the quality assessment of diagnostic accuracy studies. BMC Med Res Methodol. (2006) 6:9. doi: $10.1186 / 1471-2288-6-9$

16. Wan X, Wang W, Liu J, Tong T. Estimating the sample mean and standard deviation from the sample size, median, range and/or interquartile range. BMC Med Res Methodol. (2014) 14:135. doi: 10.1186/1471-2288-14-135

17. edited by Julian PTH, Sally G. Cochrane Handbook for Systematic Reviews of Interventions: Chichester. West Sussex Hoboken NJ: John Wiley \&amp Sons, [2008] @2008 (2008).

18. Singh JA, Saag KG, Bridges SL Jr, Akl EA, Bannuru RR, Sullivan MC, et al. American college of rheumatology guideline for the treatment of rheumatoid arthritis. Arthritis Care Res. (2016) 68:1-25. doi: 10.1002/acr.22783

19. Grundy SM, Stone NJ, Bailey AL, Beam C, Birtcher KK, Blumenthal RS, et al. 2018 AHA/ACC/AACVPR/AAPA/ABC/ACPM/ADA/AGS/APhA/ASPC/NLA/PCNA guideline on the management of blood cholesterol: a report of the american college of cardiology/American heart association task force on clinical practice guidelines. J Am Coll Cardiol. (2019) 73:e285-350. doi: 10.1016/j.jacc.2018.11.004

20. Masic D, Stengaard-Pedersen K, Logstrup BB, Horslev-Petersen K, Hetland ML, Junker P, et al. Similar lipid level changes in early rheumatoid arthritis patients following 1-year treat-to-target strategy with adalimumab plus methotrexate versus placebo plus methotrexate: secondary analyses from the randomised controlled OPERA trial. Rheumatol Int. (2021) 41:5439. doi: 10.1007/s00296-020-04756-5

21. Giles JT, Sattar N, Gabriel S, Ridker PM, Gay S, Warne C, et al. Cardiovascular Safety of Tocilizumab Versus Etanercept in Rheumatoid Arthritis: A Randomized Controlled Trial. Arthritis Rheumatol. (2020) 72:3140. doi: 10.1002/art.41095

22. Corrado A, Colia R, Rotondo C, Sanpaolo E, Cantatore FP. Changes in serum adipokines profile and insulin resistance in patients with rheumatoid arthritis treated with anti-TNF-alpha. Curr Med Res Opin. (2019) 35:2197205. doi: $10.1080 / 03007995.2019 .1654988$

23. Virone A, Bastard JP, Fellahi S, Capeau J, Rouanet S, Sibilia J, et al. Comparative effect of tumour necrosis factor inhibitors versus other biological agents on cardiovascular risk-associated biomarkers in patients with rheumatoid arthritis. RMD open. (2019) 5:e000897. doi: 10.1136/rmdopen-2019-000897

24. Bergstrom U, Jovinge S, Persson J, Jacobsson LTH, Turesson C. Effects of treatment with adalimumab on blood lipid levels and atherosclerosis in patients with rheumatoid arthritis. Curr Ther Res Clin Exp. (2018) 89:16. doi: 10.1016/j.curtheres.2018.07.001

25. Rodriguez-Carrio J, Alperi-Lopez M, Lopez P, Lopez-Mejias R, Alonso-Castro $\mathrm{S}$, Abal F, et al. High triglycerides and low high-density lipoprotein cholesterol lipid profile in rheumatoid arthritis: A potential link among inflammation, oxidative status, and dysfunctional high-density lipoprotein. J Clin Lipidol. (2017) 11:1043-54 e2. doi: 10.1016/j.jacl.2017.05.009

26. O'Neill F, Charakida M, Topham E, McLoughlin E, Patel N, Sutill E, et al. Anti-inflammatory treatment improves highdensity lipoprotein function in rheumatoid arthritis. Heart. (2017) 103:766-73. doi: 10.1136/heartjnl-2015-308953

27. Gabay C, McInnes IB, Kavanaugh A, Tuckwell K, Klearman M, Pulley $\mathrm{J}$, et al. Comparison of lipid and lipid-associated cardiovascular risk marker changes after treatment with tocilizumab or adalimumab in patients with rheumatoid arthritis. Ann Rheum Dis. (2016) 75:180612. doi: 10.1136/annrheumdis-2015-207872

28. Charles-Schoeman C, Wang X, Lee YY, Shahbazian A, Navarro-Millan I, Yang $S$, et al. Association of triple therapy with improvement in cholesterol profiles over two-year followup in the treatment of early aggressive rheumatoid arthritis trial. Arthritis Rheumatol. (2016) 68:577-86. doi: 10.1002/art.39502

29. Bissell LA, Hensor EM, Kozera L, Mackie SL, Burska AN, Nam JL, et al. Improvement in insulin resistance is greater when infliximab is added to methotrexate during intensive treatment of early rheumatoid arthritis-results from the IDEA study. Rheumatology. (2016) 55:218190. doi: 10.1093/rheumatology/kew306

30. Deodhar A, Bitman B, Yang Y, Collier DH. The effect of etanercept on traditional metabolic risk factors for cardiovascular disease in patients with rheumatoid arthritis. Clin Rheumatol. (2016) 35:3045-52. doi: 10.1007/s10067-016-3422-7

31. Ronda N, Greco D, Adorni MP, Zimetti F, Favari E, Hjeltnes G, et al. Newly identified antiatherosclerotic activity of methotrexate and adalimumab: complementary effects on lipoprotein function and macrophage cholesterol metabolism. Arthritis Rheumatol. (2015) 67:1155-64. doi: 10.1002/art.39039

32. Chen DY, Chen YM, Hsieh TY, Hsieh CW, Lin CC, Lan JL. Significant effects of biologic therapy on lipid profiles and insulin resistance in patients with rheumatoid arthritis. Arthritis Res Ther. (2015) 17:52. doi: 10.1186/s13075-015-0559-8

33. Rodriguez-Jimenez NA, Garcia-Gonzalez CE, Ayala-Lopez KP, TrujilloHernandez B, Aguilar-Chavez EA, Rocha-Munoz AD, et al. Modifications in lipid levels are independent of serum TNF-alpha in rheumatoid arthritis: results of an observational 24-week cohort study comparing patients receiving etanercept plus methotrexate or methotrexate as monotherapy. Biomed Res Int. (2014) 2014:510305. doi: 10.1155/2014/510305

34. Cacciapaglia F, Anelli MG, Rinaldi A, Serafino L, Covelli M, Scioscia C, et al. Lipid profile of rheumatoid arthritis patients treated with anti-tumor necrosis factor-alpha drugs changes according to disease activity and predicts clinical response. Drug Dev Res. (2014) 75:S77-80. doi: 10.1002/ddr.21203

35. Calvo Alén J, Baamonde C, Villa I, Peña JL, Gómez-Gerique J. AB0270 Anti-tnf therapy induces positive changes in the lipoprotein profile of ra patientes. results of a prospective study. Ann Rheumatic Dis. (2014) 72:A868.3-A. doi: 10.1136/annrheumdis-2013-eular.2592

36. Hjeltnes G, Hollan I, Førre O, Wiik A, Lyberg T, Mikkelsen K, et al. nRCTSerum levels of lipoprotein(a) and E-selectin are reduced in rheumatoid arthritis patients treated with methotrexate or methotrexate in combination with TNF- $\alpha$-inhibitor. Clin Exp Rheumatol. (2013) 31:415-21.

37. Chen CY, Tsai CY, Lee PC, Lee SD. Long-term etanercept therapy favors weight gain and ameliorates cachexia in rheumatoid arthritis patients: roles of gut hormones and leptin. Curr Pharm Des. (2013) 19:195664. doi: $10.2174 / 1381612811319100014$

38. Sandoo A, van Zanten JJ, Toms TE, Carroll D, Kitas GD. AntiTNFalpha therapy transiently improves high density lipoprotein cholesterol levels and microvascular endothelial function in patients with rheumatoid arthritis: a pilot study. BMC Musculoskelet Disord. (2012) 13:127. doi: $10.1186 / 1471-2474-13-127$

39. Senel S, Cobankara V, Taskoylu O, Karasu U, Karapinar H, Erdis E, et al. The safety and efficacy of etanercept on cardiac functions and lipid profile in patients with active rheumatoid arthritis. J Investigat Med. (2012) 60:625. doi: 10.2310/JIM.0b013e31823a00f4

40. Tam LS, Shang Q, Li EK, Lee KL, Leung YY, Ying KY, et al. Infliximab is associated with improvement in arterial stiffness in patients with early rheumatoid arthritisa randomized trial. Arthritis Rheumatism. (2012) 63:2267-75. doi: 10.3899/jrheum.120541 
41. Ajeganova S, Fiskesund R, De Faire U, Hafström I, Frostegård J. nRCTEffect of biological therapy on levels of atheroprotective antibodies against phosphorylcholine and apolipoproteins in rheumatoid arthritis: a one-year study. Clin Exp Rheumatol. (2011) 29:942-50.

42. Kume K, Amano K, Yamada S, Hatta K, Ohta H, Kuwaba N. Tocilizumab monotherapy reduces arterial stiffness as effectively as etanercept or adalimumab monotherapy in rheumatoid arthritis: an open-label randomized controlled trial. J Rheumatol. (2011) 38:2169-71. doi: 10.3899/jrheum.110340

43. Jamnitski A, Visman IM, Peters MJ, Dijkmans BA, Voskuyl AE, Nurmohamed MT. Beneficial effect of 1-year etanercept treatment on the lipid profile in responding patients with rheumatoid arthritis: the ETRA study. Ann Rheum Dis. (2010) 69:1929-33. doi: 10.1136/ard.2009.127597

44. Engvall IL, Tengstrand B, Brismar K, Hafstrom I. Infliximab therapy increases body fat mass in early rheumatoid arthritis independently of changes in disease activity and levels of leptin and adiponectin: a randomised study over 21 months. Arthritis Res Ther. (2010) 12:R197. doi: 10.1186/ar3169

45. Derdemezis CS, Filippatos TD, Voulgari PV, Tselepis AD, Drosos AA, Kiortsis DN. Effects of a 6-month infliximab treatment on plasma levels of leptin and adiponectin in patients with rheumatoid arthritis. Fundam Clin Pharmacol. (2009) 23:595-600. doi: 10.1111/j.1472-8206.2009.00717.x

46. Wijbrandts CA, van Leuven SI, Boom HD, Gerlag DM, Stroes EG, Kastelein JJ, et al. Sustained changes in lipid profile and macrophage migration inhibitory factor levels after anti-tumour necrosis factor therapy in rheumatoid arthritis. Ann Rheum Dis. (2009) 68:1316-21. doi: 10.1136/ard.2007.086728

47. Popa C, van Tits LJ, Barrera P, Lemmers HL, van den Hoogen FH, van Riel PL, et al. Anti-inflammatory therapy with tumour necrosis factor alpha inhibitors improves high-density lipoprotein cholesterol antioxidative capacity in rheumatoid arthritis patients. Ann Rheum Dis. (2009) 68:86872. doi: 10.1136/ard.2008.092171

48. Soubrier M, Jouanel P, Mathieu S, Poujol D, Claus D, Dubost JJ, et al. Effects of anti-tumor necrosis factor therapy on lipid profile in patients with rheumatoid arthritis. Joint Bone Spine. (2008) 75:22-4. doi: 10.1016/j.jbspin.2007.04.014

49. Nishida K, Okada Y, Nawata M, Saito K, Tanaka Y. Induction of hyperadiponectinemia following long-term treatment of patients with rheumatoid arthritis with infliximab (IFX), an anti-TNF-alpha antibody. Endocr J. (2008) 55:213-6. doi: 10.1507/endocrj.K07E-043

50. Bosello S, Santoliquido A, Zoli A, Di Campli C, Flore R, Tondi P, et al. TNF-alpha blockade induces a reversible but transient effect on endothelial dysfunction in patients with long-standing severe rheumatoid arthritis. Clin Rheumatol. (2008) 27:833-9. doi: 10.1007/s10067-007-0803-y

51. Tam LS, Tomlinson B, Chu TT Li TK, Li EK. Impact of TNF inhibition on insulin resistance and lipids levels in patients with rheumatoid arthritis. Clin Rheumatol. (2007) 26:1495-8. doi: 10.1007/s10067-007-0539-8

52. Popa C, van den Hoogen FH, Radstake TR, Netea MG, Eijsbouts AE, den Heijer $\mathrm{M}$, et al. Modulation of lipoprotein plasma concentrations during long-term anti-TNF therapy in patients with active rheumatoid arthritis. Ann Rheum Dis. (2007) 66:1503-7. doi: 10.1136/ard.2006.066191

53. Peters MJ, Vis M, van Halm VP, Wolbink GJ, Voskuyl AE, Lems WF, et al. Changes in lipid profile during infliximab and corticosteroid treatment in rheumatoid arthritis. Ann Rheum Dis. (2007) 66:95861. doi: 10.1136/ard.2006.059691

54. Oguz FM, Oguz A, Uzunlulu M. The effect of infliximab treatment on insulin resistance in patients with rheumatoid arthritis. Acta Clin Belg. (2007) 62:218-22. doi: 10.1179/acb.2007.035

55. Komai N, Morita Y, Sakuta T, Kuwabara A, Kashihara N. Anti-tumor necrosis factor therapy increases serum adiponectin levels with the improvement of endothelial dysfunction in patients with rheumatoid arthritis. Modern Rheumatol. (2007) 17:385-90. doi: 10.3109/s10165-007-0605-8

56. Seriolo B, Paolino S, Sulli A, Fasciolo D, Cutolo M. Effects of antiTNF-alpha treatment on lipid profile in patients with active rheumatoid arthritis. Ann N Y Acad Sci. (2006) 1069:414-9. doi: 10.1196/annals. 1351.039

57. Dahlqvist SR, Engstrand S, Berglin E, Johnson O. Conversion towards an atherogenic lipid profile in rheumatoid arthritis patients during long-term infliximab therapy. Scand J Rheumatol. (2006) 35:107-11. doi: 10.1080/03009740500474578

58. Allanore Y, Kahan A, Sellam J, Ekindjian OG, Borderie D. Effects of repeated infliximab therapy on serum lipid profile in patients with refractory rheumatoid arthritis. Clin Chimica Acta Int J Clin Chem. (2006) 365:1438. doi: 10.1016/j.cca.2005.08.010

59. Gonzalez-Juanatey C, Llorca J, Andrade AS, Garcia-Porrua C, Martin J, Gonzalez-Gay MA. Short-term adalimumab therapy improves endothelial function in patients with rheumatoid arthritis refractory to infliximab. Clin Exp Rheumatol. (2006) 24:309-12.

60. Spanakis E, Sidiropoulos P, Papadakis J, Ganotakis E, Katsikas G, Karvounaris $\mathrm{S}$, et al. Modest but sustained increase of serum high density lipoprotein cholesterol levels in patients with inflammatory arthritides treated with infliximab. J Rheumatol. (2006) 33:2440-6.

61. Popa C, Netea MG, Radstake T, Van der Meer JW, Stalenhoef AF, van Riel PL, et al. Influence of anti-tumour necrosis factor therapy on cardiovascular risk factors in patients with active rheumatoid arthritis. Ann Rheum Dis. (2005) 64:303-5. doi: 10.1136/ard.2004.023119

62. Vis M, Nurmohamed MT, Wolbink G, Voskuyl AE, de Koning M, van de Stadt $\mathrm{R}$, et al. Short term effects of infliximab on the lipid profile in patients with rheumatoid arthritis. J Rheumatol. (2005) 32:252-5.

63. Irace C, Mancuso G, Fiaschi E, Madia A, Sesti G, Gnasso A. Effect of anti TNFalpha therapy on arterial diameter and wall shear stress and HDL cholesterol. Atherosclerosis. (2004) 177:113-8. doi: 10.1016/j.atherosclerosis.2004.04.031

64. Moreland LW, O'Dell JR, Paulus HE, Curtis JR, Bathon JM, St Clair EW, et al. A randomized comparative effectiveness study of oral triple therapy versus etanercept plus methotrexate in early aggressive rheumatoid arthritis: the treatment of Early Aggressive Rheumatoid Arthritis Trial. Arthritis Rheum. (2012) 64:2824-35. doi: 10.1002/art.34498

65. Pollono EN, Lopez-Olivo MA, Lopez JA, Suarez-Almazor ME, A. systematic review of the effect of TNF-alpha antagonists on lipid profiles in patients with rheumatoid arthritis. Clin Rheumatol. (2010) 29:947-55. doi: 10.1007/s10067-010-1405-7

66. Popa C, Netea MG, van Riel PL, van der Meer JW, Stalenhoef AF. The role of TNF-alpha in chronic inflammatory conditions, intermediary metabolism, and cardiovascular risk. J Lipid Res. (2007) 48:751-62. doi: 10.1194/jlr.R600021-JLR200

67. Charles-Schoeman C, Fleischmann R, Davignon J, Schwartz H, Turner SM, Beysen C, et al. Potential mechanisms leading to the abnormal lipid profile in patients with rheumatoid arthritis versus healthy volunteers and reversal by tofacitinib. Arthritis Rheumatol. (2015) 67:616-25. doi: 10.1002/art.38974

68. Schmucker CM, Blümle A, Schell LK, Schwarzer G, Oeller P, Cabrera L, et al. Systematic review finds that study data not published in full text articles have unclear impact on meta-analyses results in medical research. PLOS ONE. (2017) 12:e0176210. doi: 10.1371/journal.pone.0176210

69. Hoffman JS, Benditt EP. Plasma clearance kinetics of the amyloid-related high density lipoprotein apoprotein, serum amyloid protein (apoSAA), in the mouse. Evidence for rapid apoSAA clearance. J Clin Invest. (1983) 71:92634. doi: 10.1172/JCI110847

70. Zewinger S, Drechsler C, Kleber ME, Dressel A, Riffel J, Triem S, et al. Serum amyloid A: high-density lipoproteins interaction and cardiovascular risk. Eur Heart J. (2015) 36:3007-16. doi: 10.1093/eurheartj/ehv352

71. Han CY, Tang C, Guevara ME, Wei H, Wietecha T, Shao B, et al. Serum amyloid A impairs the antiinflammatory properties of HDL. J Clin Invest. (2016) 126:266-81. doi: 10.1172/JCI83475

72. Vallon R, Freuler F, Desta-Tsedu N, Robeva A, Dawson J, Wenner P, et al. Serum amyloid A (apoSAA) expression is up-regulated in rheumatoid arthritis and induces transcription of matrix metalloproteinases. J Immunol. (2001) 166:2801-7. doi: 10.4049/jimmunol.166.4.2801

73. Jia C, Anderson JLC, Gruppen EG, Lei Y, Bakker SJL, Dullaart RPF, et al. High-density lipoprotein anti-inflammatory capacity and incident cardiovascular events. Circulation. (2021) 143:193545. doi: 10.1161/CIRCULATIONAHA.120.050808

74. Bhattacharyya T, Nicholls SJ, Topol EJ, Zhang R, Yang X, Schmitt D, et al. Relationship of paraoxonase 1 (PON1) gene polymorphisms and functional activity with systemic oxidative stress and cardiovascular risk. JAMA. (2008) 299:1265-76. doi: 10.1001/jama.299.11.1265

75. Charles-Schoeman C, Lee YY, Shahbazian A, Gorn AH, Fitzgerald J, Ranganath VK, et al. Association of paraoxonase 1 gene polymorphism and enzyme activity with carotid plaque in rheumatoid arthritis. Arthritis Rheum. (2013) 65:2765-72. doi: 10.1002/art.38118 
76. Bae SC, Lee YH. Associations between paraoxonase 1 (PON1) polymorphisms and susceptibility and PON1 activity in rheumatoid arthritis patients, and comparison of PON1 activity in patients and controls: a meta-analysis. Clin Rheumatol. (2019) 38:2141-9. doi: 10.1007/s10067-019-04499-0

77. Charles-Schoeman C, Wang J, Shahbazian A, Lee YY, Wang X, Grijalva V, et al. Suppression of inflammatory arthritis in human serum paraoxonase 1 transgenic mice. Sci Rep. (2020) 10:16848. doi: 10.1038/s41598-020-74016-w

78. Kumon Y, Suehiro T, Ikeda Y, Hashimoto K. Human paraoxonase-1 gene expression by HepG2 cells is downregulated by interleukin-1 $\beta$ and tumor necrosis factor- $\alpha$, but is upregulated by interleukin-6. Life Sci. (2003) 73:280715. doi: 10.1016/S0024-3205(03)00704-5

79. Liu C, Batliwalla F, Li W, Lee A, Roubenoff R, Beckman E, et al. Genomewide association scan identifies candidate polymorphisms associated with differential response to anti-TNF treatment in rheumatoid arthritis. Mol Med. (2008) 14:575-81. doi: 10.2119/2008-00056.Liu

80. Odobasic D, Yang Y, Muljadi RC, O'Sullivan KM, Kao W, Smith M, et al. Endogenous myeloperoxidase is a mediator of joint inflammation and damage in experimental arthritis. Arthritis Rheumatol. (2014) 66:90717. doi: 10.1002/art.38299

81. Alisik T, Alisik M, Nacir B, Ayhan FF, Genc H, Erel O. Evaluation of dysfunctional high-density lipoprotein levels with myeloperoxidase/paraoxonase-1 ratio in rheumatoid arthritis. Int J Clin Pract. (2021) n/a(n/a):e14172. doi: 10.1111/ijcp.14172

82. Vivekanandan-Giri A, Slocum JL, Byun J, Tang C, Sands RL, Gillespie BW, et al. High density lipoprotein is targeted for oxidation by myeloperoxidase in rheumatoid arthritis. Ann Rheum Dis. (2013) 72:1725-31. doi: 10.1136/annrheumdis-2012-202033

83. Charles-Schoeman C, Lee YY, Grijalva V, Amjadi S, FitzGerald J, Ranganath VK, et al. Cholesterol efflux by high density lipoproteins is impaired in patients with active rheumatoid arthritis. Ann Rheum Dis. (2012) 71:115762. doi: 10.1136/annrheumdis-2011-200493

84. Tejera-Segura B, Macia-Diaz M, Machado JD, de Vera-Gonzalez A, Garcia-Dopico JA, Olmos JM, et al. HDL cholesterol efflux capacity in rheumatoid arthritis patients: contributing factors and relationship with subclinical atherosclerosis. Arthritis Res Ther. (2017) 19:113. doi: 10.1186/s13075-017-1311-3

85. Liao KP, Playford MP, Frits M, Coblyn JS, Iannaccone C, Weinblatt ME, et al. The association between reduction in inflammation and changes in lipoprotein levels and HDL cholesterol efflux capacity in rheumatoid arthritis. J Am Heart Assoc. (2015) 4:e001588. doi: 10.1161/JAHA.114.001588

86. Voloshyna I, Seshadri S, Anwar K, Littlefield MJ, Belilos E, Carsons SE, et al. Infliximab reverses suppression of cholesterol efflux proteins by TNF-alpha: a possible mechanism for modulation of atherogenesis. Biomed Res Int. (2014) 2014:312647. doi: 10.1155/2014/312647
87. Ly H, Francone OL, Fielding CJ, Shigenaga JK, Moser AH, Grunfeld C, et al. Endotoxin and TNF lead to reduced plasma LCAT activity and decreased hepatic LCAT mRNA levels in Syrian hamsters. J Lipid Res. (1995) 36:125463. doi: 10.1016/S0022-2275(20)41133-2

88. Hardardottir I, Moser AH, Fuller J, Fielding C, Feingold K, Grunfeld C. Endotoxin and cytokines decrease serum levels and extra hepatic protein and mRNA levels of cholesteryl ester transfer protein in syrian hamsters. J Clin Invest. (1996) 97:2585-92. doi: 10.1172/JCI118707

89. Hernandez-Hernandez V, Ferraz-Amaro I, Delgado-Frías E, FloresRodríguez M, Viotti J, Rodríguez de la Rosa C, et al. Role of cholesterol ester transfer protein in inflammation mediated dyslipidemia of rheumatoid arthritis patients. Ann Rheumatic Dis. (2014) 71:657. doi: 10.1136/annrheumdis-2012-eular.339

90. Ursini F, Leporini C, Bene F, D’Angelo S, Mauro D, Russo E, et al. Anti-TNF-alpha agents and endothelial function in rheumatoid arthritis: a systematic review and meta-analysis. Sci Rep. (2017) 7:5346. doi: 10.1038/s41598-017-05759-2

91. Gordon DJ, Probstfield JL, Garrison RJ, Neaton JD, Castelli WP, Knoke JD, et al. High-density lipoprotein cholesterol and cardiovascular disease. Four prospective American studies. Circulation. (1989) 79:8-15. doi: 10.1161/01.CIR.79.1.8

92. Kirkham BW, Wasko MC, Hsia EC, Fleischmann RM, Genovese MC, Matteson EL, et al. Effects of golimumab, an anti-tumour necrosis factor-alpha human monoclonal antibody, on lipids and markers of inflammation. Ann Rheum Dis. (2014) 73:161-9. doi: 10.1136/annrheumdis-2012-202089

Conflict of Interest: The authors declare that the research was conducted in the absence of any commercial or financial relationships that could be construed as a potential conflict of interest.

Publisher's Note: All claims expressed in this article are solely those of the authors and do not necessarily represent those of their affiliated organizations, or those of the publisher, the editors and the reviewers. Any product that may be evaluated in this article, or claim that may be made by its manufacturer, is not guaranteed or endorsed by the publisher.

Copyright (C) 2021 Luo, Ren, Weng, Yan, Mao and Peng. This is an open-access article distributed under the terms of the Creative Commons Attribution License (CC $B Y)$. The use, distribution or reproduction in other forums is permitted, provided the original author(s) and the copyright owner(s) are credited and that the original publication in this journal is cited, in accordance with accepted academic practice. No use, distribution or reproduction is permitted which does not comply with these terms. 